\title{
The modern evaluation method of fracture toughness of basaltplastic lining for engineering collectors
}

\author{
Olga Lyapidevskaya ${ }^{*}$, and Andrey Sherstnev ${ }^{1}$ \\ ${ }^{1}$ Moscow State University of Civil Engineering, Yaroslavskoe sh. 26, 129337 Moscow, Russia
}

\begin{abstract}
The estimation methods of fracture toughness of reinforced blocks are considered for construction for engineering collectors. There are presented the methodical accesses that make possible to numerical describe all studies of destruction process of polymer lining with regard to simultaneously action the whole complex of exploitation factors. It is stated the data of fracture toughness of the composites on organic and nonorganic matrix in normal condition in comparison with basaltplastic lining. It is reported the dates of safety and critical coefficients of composite strains intensity on organic and nonorganic base in normal conditions.
\end{abstract}

\section{Methods of evaluation of fracture}

The fracture toughness is the one of the most important characteristic of safety of polymer lining.

Processing from the fracture toughness condition under action of the exploitation load it is determined the thickness of polymer lining. It is a number of evaluation methods of estimation of the fracture toughness that permit to determine the possibility of material to be resistant to developing of stress (to failure).

This paper is presented the modern method of estimation of the fracture toughness and comparative analysis of composites on the base of organic and nonorganic matrix with basaltplastic.

The basaltplastic lining is the special multi-layered lining consisted from nano modified thermosetting resins, chopped basalt fibers, metal reinforcing elements for coupling of lining with concrete that is designed to protect the inner surfaces of concrete blocks from possible mechanical, thermal, physical and chemical damage.

For the formulation and solution of this task the plane of polymer lining was combined with the plane of a Cartesian coordinate system with respect to which it was set orientation and location ordered the cyclically symmetric system of fibers in composite (fig. 1).

\footnotetext{
* Corresponding author : olga.lyapidevskaya@inbox.ru
} 


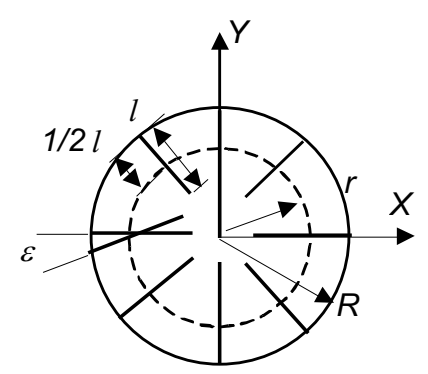

Fig. 1. The model of randomly reinforced basaltplastic by discrete fibers: 1- the length of rigid inclusion, $\mathrm{R}$ - the radius of the composite, $\varepsilon$ - the angle of rotation of the rigid inclusion.

On the basis of application of the method of mechanical quadrature to calculate the ratio of intensity stresses in the work [1] it was established that giving the length of the fibers $\mathrm{L}$ and values $\mathrm{K}_{\mathrm{o}}$ and $\mathrm{K}_{\mathrm{q}}$ can be found the values of $\sigma_{\mathrm{o}}$ and $\sigma_{\mathrm{k}}$ :

$$
\sigma_{0}=\frac{K_{0}}{0.0604 \sqrt{l}} ; \sigma_{k}=\frac{K_{q}}{0.0604 \sqrt{l}}
$$

where $\sigma_{\mathrm{o}}$ - safety stress, $\sigma_{\mathrm{k}}$ - critical stress, that are substantial data when assessing bearing capacity of the material. Therefore, the values $\sigma_{0}, \sigma_{k}, K_{o}$ and $K_{q}$ are connected by the next ratio:

$$
\frac{\sigma_{0}}{\sigma_{q}}=\frac{K_{0}}{K_{q}}
$$

The legitimacy of the use of methods of linear mechanics of destruction for the investigation of fracture toughness of polymer and composites on its base is proven by the results of a number of works.

The paper [2] presents the results of experimental determination fracture toughness of epoxy resin. Straightforward character typical chart "stress - offset", and also the consistency of critical factor of intensity stresses K1c evidence of the legality of relevant application of linear fracture mechanics.

In the work [3] it is analysed the possibility of using the classical methods of destruction for investigation of cracks developing processes in composite materials and showed that at the macro level to composites may be applied such concepts as the coefficient of stress intensity, the rate of release of strain energy, he critical crack opening, $\mathrm{J}$ - integral. To determine the strength properties of composites with cracks the authors of the works $[4,5]$ suggest to use well-developed methods of fracture mechanics of homogeneous anisotropic body.

However linear fracture mechanics may be used to estimate the fracture toughness only to composites having linear elastic properties until the destruction. Quite often the destruction of the material is preceded by the formation of a prefracture zone in the vicinity of crack tip (tears and elongation of individual fibers, loosening of the matrix and violation of adhesion on the interface) that starts with a load equal to $80 \%$ of the critical [6]. When this zone is small compared to the size of the defect which cause the destruction of the composite it is possible to apply methods of linear mechanics to such materials [3], and in particular, the concept of the $\mathrm{K}$ coefficient, introducing an amendment to Irvine [7], lengthening the initial crack at a certain amount: 


$$
r_{y}=\frac{1}{2 \pi}\left(\frac{K_{1 c}}{\sigma_{0,2}}\right)^{2}
$$

where $\sigma_{0,2}$ - the yield strength of the material.

Effective fracture length $-\mathrm{L}_{\mathrm{ef}}=\mathrm{L}_{0}+\mathrm{r}_{\mathrm{y}}$.

The authors of the work [8] suggested for estimation of crack resistance of randomly reinforced fiberglass on the base of epoxy and polyester resins to use the method R-curve, which is widely used to describe the behaviour of metallic materials at destruction [6]. The essence of the method of R-curve lies is to estimate the increment of crack length at the time of its unstable distribution. The meaning of this is analogous to the reception of Jones and Brown's in determining coefficient $\mathrm{K}_{\mathrm{q}}$ corresponding to the two per cent tolerance on stable growth of crack when tested to destruction. The plate specimens with edge crack were tested. The coefficient of stress intensity was determined [9] by the formula:

$$
K=\frac{P a^{0.5}}{t H} Y
$$

where Y- the shape factor of the sample coefficient, a - the length of crack corresponding to the load $\mathrm{P} ; \mathrm{t}$ and $\mathrm{H}$ - the thickness and the width of the test sample respectively.

The results of the work [6] showed that the method R-curve can be successfully applied to composite chaotic reinforced materials with developed prefracture zone.

\section{The modern method of fracture assessment}

The above experimental approaches to the evaluation of performance of composites from the position of linear fracture mechanics do not give total information about the parameters of fracture toughness of composite materials as in normal condition as in terms of the impact of operational factors (temperature, aggressive environment, load and so on), since the fracture toughness is evaluated only at the stage of propagation of the macrocrack, which is the second final part of a long process of destruction.

Thus, it is obvious that for modern composite materials it is necessary the methodological approaches to quantitatively describe all the stages of the process of destruction of the material subject to the simultaneous exposure of the whole complex of operational factors.

Thus, the main fundamental characteristic of composites is the coefficient of stress intensity. Knowing the latest it is possible to estimate the stress-strain state in the vicinity of the most dangerous areas of the composite, its load capacity (since most of the criteria for the occurrence of the threat condition are expressed through the components of the stress tensor), and to establish the effect of operational factors.

The basis for determining the critical stress intensity factor $\mathrm{K}$ for the case of generalized plane stress state the condition defined at the moment of breakaway of a crack-cuts were based on the methodology outlined in this paper 9 .

\section{The results of laboratory fracture tests of composite materials using modern method of its evaluation}

The choice of this technique is predefined with the shape of test specimen that is a wedge-shaped sample of type a double console beam, allows long to exhibit it in terms simultaneous exposure to different aggressive spheres, load and temperature (fig. 2). 


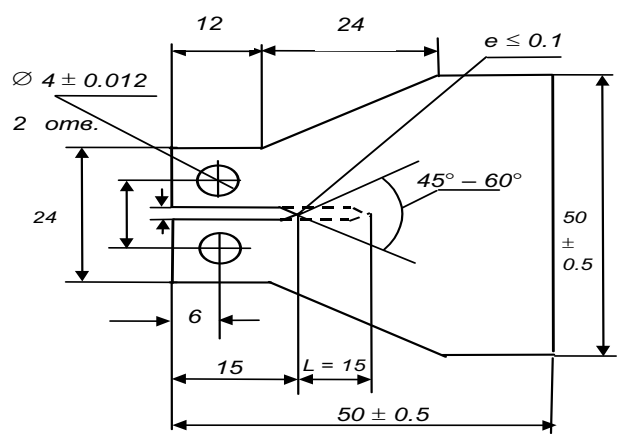

Fig. 2. A wedge-shaped sample of type a double console beam: L- the valid range of initial crackincision $\mathrm{n}$ lengths, $\mathrm{e}-\mathrm{its}$ width.

A wedge-shaped sample was stretched on a tensile testing machine at a speed of the active capture $1-0,5 \mathrm{~mm} / \mathrm{min}$. The error in determining the power does not exceed $10 \%$ of the measured value [10].

To determine the moment of breakaway of a crack-cut it was proposed simultaneously with the recording of the curve "force-displacement" record in real time the differential and integral parameters of acoustic emission (fig. 3).

Experimentally it was found that the minimum pulse amplitude acoustic emission associated with the beginning of the micro fractures of the tested components is $50 \mu \mathrm{v}$. Pulses with the amplitude of $10 \mu \mathrm{v}$ relate to fluctuation noise. The acoustic emission signals with an amplitude less than $100 \mu \mathrm{v}$ reflect the kinetics of accumulation of submicron cracks in the vicinity of crack tip of the notch and readiness to start.

For the moving crack front-cut is taken as the time of occurrence of the characteristic "jump" in the diagram "stress-displacement" $X$ [11]. In the absence of a specified characteristic "jump" for the moving is taken as the time of appearance of acoustic emission signals exceeding $150 \mu \mathrm{v}$.
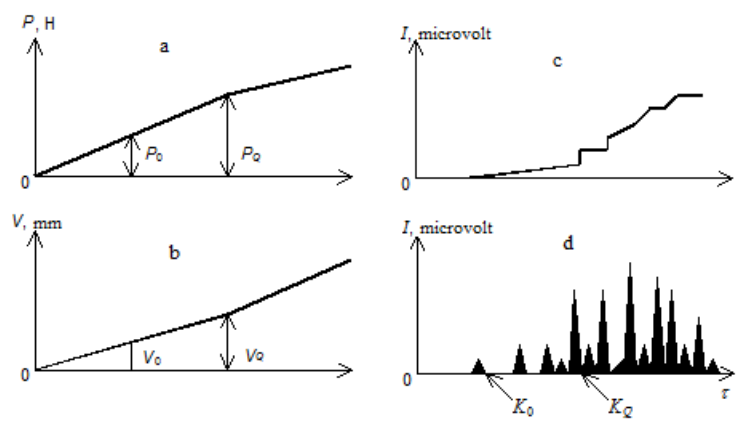

Fig. 3. Synchronized recording: a - stress $\mathrm{P}$, b- displacement V, c - the amount of acoustic emission pulses, $\mathrm{d}$ - the acoustic emission signals.

Believing that the process of microfractures of a composite is the process of nucleation of microcracks we denote the stress intensity factor corresponding to this process, $-\mathrm{K}_{0}$.

In establishing the diagram "force-displacement" at the outbreak of the first acoustic emission signals and the pushing-notch fracture the amount of $\mathrm{K}_{\mathrm{o}}$ and $\mathrm{K}_{\mathrm{g}}$ are determine by the relations:

$$
K_{0}=\sqrt{\frac{P_{0} E V_{0}}{2 b l}} ; K_{q}=\sqrt{\frac{P_{q} E V_{q}}{2 b l}}
$$


where $\mathrm{P}_{0}$ and $\mathrm{P}_{\mathrm{q}}$ - load, respectively at the time of the first signal of acoustic emission and breakaway crack; $\mathrm{V}_{0}$ and $\mathrm{V}_{\mathrm{q}}$ - disclosure of the crack, respectively, at the time of the first acoustic emission signal cracks and breakaway; $b$ - the thickness of the sample in the vicinity of the top of the notch-cracks, 1 - the original length of the crack notch.

Table 1. The fracture toughness data based composites of inorganic and organic matrix in normal conditions.

\begin{tabular}{|c|c|c|c|}
\hline Resin, composite & $\begin{array}{c}\text { The content of the } \\
\text { reinforcing component, } \\
\text { max. } \%\end{array}$ & $\mathbf{K}_{\mathbf{q}}, \mathbf{N} / \mathbf{m m}^{\mathbf{3} \mathbf{2}}$ & $\begin{array}{c}\text { The coefficient of } \\
\text { variation, } \%\end{array}$ \\
\hline PN -15 & - & 19.1 & 9.0 \\
\hline PN -15+ lavsan & 10 & 28.0 & 12.1 \\
\hline PN -15+MPS & 10 & 30.5 & 11.9 \\
\hline PN -15+LBB-SP & 10 & 32.3 & 13.6 \\
\hline PN -15+UTM-8 & 50 & 110.2 & 14.0 \\
\hline PSK -15-SX & 50 & 101.0 & 14.8 \\
\hline PPM -15- SX & 50 & 127.3 & 15.1 \\
\hline UNIPEK+Basalt & 30 & 67.5 & 14.3 \\
\hline
\end{tabular}

Table 1 shows the fracture toughness of the composites based on organic and inorganic matrices obtained by the method described above with and without the use of acoustic emission (acoustic emission characteristic of recording signals in the process of loading the samples shown in fig. 4).

Comparison of the fracture toughness of composites parameters shows that the estimate $\mathrm{K}_{\mathrm{Q}}$ without the use of acoustic emission method materials with elasto-plastic properties which remain virtually unchanged at the start-notch fracture leads to an overestimation of the results by $6-11 \%$ compared with the data obtained using the acoustic emission method.

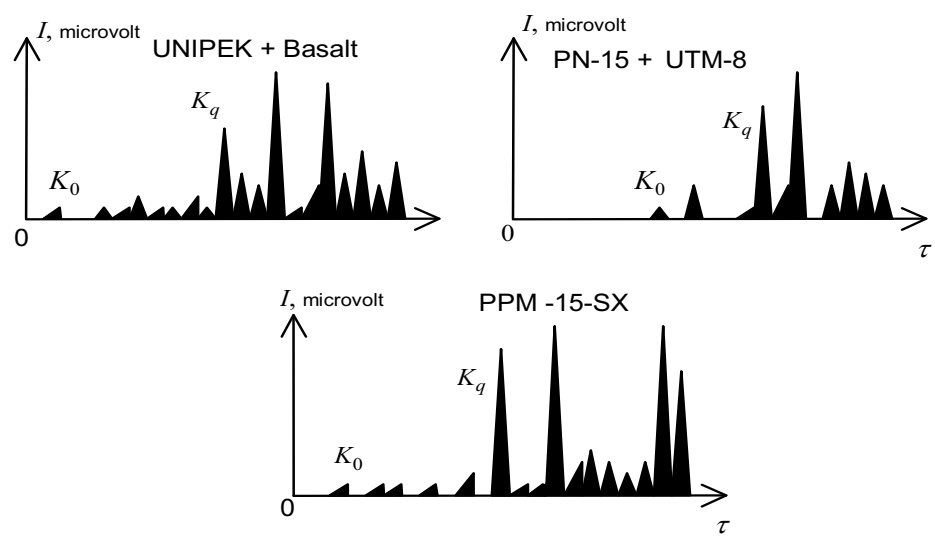

Fig. 4. The characteristic acoustic emission signals during the destruction of samples of composite materials.

The $\mathrm{K}_{0}$ and $\mathrm{K}_{\mathrm{q}}$ values of composite materials based on polyester resins PN-15 are presented in Table 2.

Table 2. Values $\mathrm{K}_{0}$ and $\mathrm{K}_{\mathrm{q}}$ of composites based on organic and inorganic matrix in normal conditions.

\begin{tabular}{|c|c|c|c|c|}
\hline Resin, composite & $\begin{array}{c}\mathrm{K}_{0 .} \\
\mathrm{N} / \mathbf{m m}^{3 / 2}\end{array}$ & $\begin{array}{c}\text { The coefficient } \\
\text { of variation, } \%\end{array}$ & $\begin{array}{c}\mathrm{K}_{\mathrm{q}}, \\
\mathrm{N} / \mathrm{mm}^{3 / 2}\end{array}$ & $\begin{array}{c}\text { The coefficient } \\
\text { of variation, } \%\end{array}$ \\
\hline
\end{tabular}




\begin{tabular}{|c|c|c|c|c|}
\hline PN-15 & 19.1 & 9.0 & 19.1 & 9.0 \\
\hline PN-15+lavsan & 28.0 & 12.1 & 28.0 & 12.1 \\
\hline PN-15+MPS & 16.0 & 12.3 & 30.5 & 11.9 \\
\hline PN-15+DBB-SP & 13.3 & 9.2 & 32.3 & 13.6 \\
\hline PN-15+U TM-8 & 47.0 & 11.1 & 110.2 & 14.0 \\
\hline PPM-15-SX & 65.0 & 14.4 & 127.3 & 15.1 \\
\hline UNIPEK+basalt & 9.4 & 11.4 & 67.5 & 14.3 \\
\hline
\end{tabular}

Table 3 shows the values of the parameters of fracture toughness and solidity ratio of randomly reinforced fiberglass.

Analysis of the data in Table 3 leads to the conclusion about clear symbate connection $\mathrm{M}_{\mathrm{x}}, \mathrm{K}_{0}$, and $\mathrm{K}_{\mathrm{q}}$.

Table 3. Values $\mathrm{Mx}, \mathrm{K} 0$, and $\mathrm{Kq}$ of randomly reinforced fiber glass.

\begin{tabular}{|c|c|c|c|}
\hline Composite & $\mathbf{K}_{\mathbf{0}} \mathbf{~} \mathbf{N} / \mathbf{m m}^{\mathbf{3} \mathbf{2}}$ & $\mathbf{K}_{\mathbf{q}} \mathbf{N} / \mathbf{m m}^{\mathbf{3} \mathbf{2}}$ & $\mathbf{M}_{\mathbf{x}}$ \\
\hline PN-15+DBB-SP & 13.3 & 32.3 & 0.40 \\
\hline PN-16+DBB-SP & 9.1 & 23.6 & 0.29 \\
\hline PN-10+DBB-SP & 5.8 & 15.2 & 0.25 \\
\hline EDT-10+DBB-SP & 19.5 & 40.0 & 0.56 \\
\hline UNIPEK+basalt & 14.5 & 33.1 & 0.47 \\
\hline
\end{tabular}

\section{Conclusion}

Solidity ratio of randomly reinforced fiber glass is indicative of not only the strength of these composite materials and also the crack resistance. Thus, the monolithic conditions set forth above may be used to produce high strength and fracture toughness at random discrete basalt fiber-reinforced composite materials.

\section{References}

1. 1. T. Berejnitsky, (Nauk. dumka, Kiev, 1983)

2. G. Korten, Micromechanics and character of compositions breaking: Modern composite materials (Mir, Moscow, 1973)

3. G.P. Zaitsev, Problem of strength 6, 78-83 (1977)

4. N. Cornish, I. Swerdlow, T.A. Cruse, Rocketry and Astronautics 1, 45-50 (1974)

5. N. Cornish, I. Swerdlow, T.A. Cruse, J. Composite Mater. 6, 114-124 (1972)

6. C.C Poe, Eng. Fract. Mech. 2(17), 153-171 (1983)

7. Proc. of Seventh Ordnance Material Research Conf. Sagamore, 1961, P.63.

8. S. Gaggar, L.G. Broutman, Ibid. 9, (1975)

9. P. Crosly, A. Ripling, Fracture Mechanics 25, 199-221 (1981)

10. B.I. Bulgakov, T. V. Lum., Industrial and Civil Engineering. 8, 45-48 (2016)

11. E.B. Tkach, Concrete technology 7-8, 44-47 (2011) 